\title{
BMJ Open What helps and hinders the provision of healthcare that minimises treatment burden and maximises patient capacity? A qualitative study of stroke health professional perspectives
}

John Kyle, Dimitris Skleparis, Frances S Mair, Katie I Gallacher (D)

To cite: Kyle J, Skleparis D, Mair FS, et al. What helps and hinders the provision of healthcare that minimises treatment burden and maximises patient capacity? A qualitative study of stroke health professional perspectives. BMJ Open 2020;10:e034113. doi:10.1136/ bmjopen-2019-034113

- Prepublication history and additional material for this paper are available online. To view these files, please visit the journal online (http://dx.doi. org/10.1136/bmjopen-2019034113).

JK and DS are joint first authors.

Received 09 September 2019 Revised 16 December 2019 Accepted 06 February 2020
Check for updates

(C) Author(s) (or their employer(s)) 2020. Re-use permitted under CC BY-NC. No commercial re-use. See rights and permissions. Published by BMJ.

General Practice and Primary Care, Institute of Health and Wellbeing, University of Glasgow, Glasgow, UK

Correspondence to Dr Katie I Gallacher; katie.gallacher@glasgow.ac.uk

\section{ABSTRACT}

Objectives Treatment burden is the healthcare workload experienced by individuals with long-term conditions and the impact on well-being. Excessive treatment burden can negatively affect quality-of-life and adherence to treatments. Patient capacity is the ability of an individual to manage their life and health problems and is dependent on a variety of physical, psychological and social factors. Previous work has suggested that stroke survivors experience considerable treatment burden and limitations on their capacity to manage their health. We aimed to examine the potential barriers and enablers to minimising treatment burden and maximising patient capacity faced by health professionals and managers providing care to those affected by stroke.

Setting Primary and secondary care stroke services in a single health board area in Scotland.

Participants Face-to-face qualitative interviews with 21 participants including stroke consultants, nurses, physiotherapists, occupational therapists, speech and language therapists, psychologists, general practitioners and health-service managers.

Outcome measures Data were analysed using thematic analysis to ascertain any factors that influence the provision of low-burden healthcare.

Results Barriers and facilitators to the provision of healthcare that minimises treatment burden and maximises patient capacity were reported under five themes: healthcare system structure (e.g. care coordination and autonomous working); resources (e.g. availability of ward nurses and community psychologists); knowledge and awareness (e.g. adequate time and materials for optimal information delivery); availability of social care (e.g. waiting times for home adaptations or extra social support) and patient complexity (e.g. multimorbidity).

Conclusions Our findings have important implications for the design and implementation of stroke care pathways, emphasising the importance of removing barriers to health professional provision of person-centred care. This work can inform the design of interventions aimed at nurturing autonomous working by health professionals, improving communication and care coordination or ensuring availability of a named person throughout the patient journey.
Strengths and limitations of this study

- Interviews with 21 healthcare professionals and managers across the stroke patient journey.

- Recruitment, data collection and analysis were conducted as an iterative process with arising themes prompting recruitment of certain types of health professional and interview questions.

- Rigorous thematic analysis was conducted, drawing on both inductive (i.e. data-driven) and deductive (i.e. based on pre-conceived ideas) approaches, until data saturation reached. Double coding of a subset of interviews and coding clinics enhanced reliability.

- Due to the nature of qualitative research, findings should be considered as explorative and not definitive.

\section{INTRODUCTION}

There is growing interest in exploring and measuring the workload of health management experienced by people living with long-term conditions. The term 'treatment burden' defines the workload of healthcare and its effects on a person's well-being. ${ }^{1-3}$ Clinical guideline bodies have emphasised the importance of treatment burden in recently published guidelines. ${ }^{4}$ Excessive treatment burden is likely to negatively affect quality-oflife and adherence to treatments. ${ }^{56}$ Burden of Treatment Theory is a formal theory that models the relationship between patients, their social networks and healthcare services. ${ }^{2}$ Non-adherence may arise if workload outweighs a person and their wider support network's ability to manage their health, defined as patient capacity. Patient capacity is dependent on a variety of personal, physical, psychological, environmental and social factors such as frailty, health literacy, socioeconomic status, location, social support and 
cognitive functioning. ${ }^{27}$ The design and implementation of clinical guidelines and the configuration of health services are thought to influence treatment burden and capacity to manage health issues. ${ }^{278}$ For example, over investigation, poor coordination between specialities or healthcare that is difficult to access may cause difficulties for service users and lead to them feeling overburdened by health management demands.

Stroke is a common long-term condition in the primary care population. ${ }^{9}$ Stroke survivors are at risk of high levels of treatment burden due to the intensity and longevity of treatments plus stroke can influence patient capacity, for example, through effects on physical ability, cognition and mood. ${ }^{810} 11$ Additionally, stroke survivors often experience multimorbidity (two or more long-standing health conditions) and so have additional treatment work related to additional long-term conditions. ${ }^{12}$ Stroke survivors describe various types of treatment-related work including researching and understanding treatments, setting goals, interacting and negotiating with health professionals, engaging friends and family to help with organisational tasks, taking medications, attending appointments, making lifestyle changes and monitoring progress in recovery. ${ }^{8}$ They report that treatment burden arises due to either a high volume of work, for example, a high number of tablets, or because of deficiencies in the way that care is delivered, for example, an unnecessarily complicated medication regime. Stroke survivors describe their transition into the community and subsequent longer-term care as particularly problematic, and this is an aspect of care that governing bodies have identified as requiring improvement. ${ }^{810}$

Our previous research elicited the experience of treatment burden from the stroke survivor's perspective. ${ }^{810}$ To inform the development of interventions aimed at minimising treatment burden and maximising patient capacity, it is important to develop an understanding of the potential barriers and enablers to provision of such healthcare. This has been an under-researched topic to date. Our aim was to examine the potential barriers and enablers to minimising treatment burden and maximising patient capacity as viewed by stroke care managers and health professionals.

\section{METHODS}

A Research Advisory Group consisting of stroke survivors and health professionals was involved throughout the design, undertaking and reporting of this study.

\section{Recruitment of participants}

A combination of convenience and purposive sampling was used to select participants involved in the planning, management or delivery of healthcare to stroke survivors in one area of Scotland (NHS Greater Glasgow and Clyde Health Board). For inclusion, participants had to have worked within a relevant role in the past 5 years, be able to provide informed consent and be able to participate in a face-to-face interview. Initially potential participants were identified via their participation in the Scottish National Advisory Committee for Stroke, the Glasgow Stroke Managed Clinical Network, the Scottish Stroke Nurses Forum and the Scottish Stroke Allied Health Professional Forum. Potential participants were then contacted via email and those who expressed an interest were screened via telephone to ensure they met our inclusion criteria. During recruitment we continually monitored participant roles to ensure a balanced variety of healthcare professionals from throughout the stroke survivor journey were included. Analysis and recruitment were conducted as an iterative process with arising themes prompting recruitment of certain types of health professional. For example, our finding that psychology resources were limited prompted recruitment of a stroke psychologist.

\section{Data collection}

Semi-structured face-to-face qualitative interviews lasting approximately $30-60 \mathrm{~min}$ were conducted by an academic General Practitioner (GP) (JK) between January and July 2018. The participant information sheet, interview schedule and consent forms are available in online supplementary appendices 1-3. The interview schedule was underpinned by our conceptual model and taxonomy of stroke survivor treatment burden from previous work ${ }^{810}$ and by Burden of Treatment Theory. ${ }^{2}$ Interviews were digitally recorded and transcribed verbatim. No further interviews were conducted once data saturation had been reached, that is, no new themes arose during analysis.

\section{Data analysis}

Data were analysed using thematic analysis; a method for searching, identifying and analysing patterns of meaning or themes, in a dataset. ${ }^{13} 14$ Thematic analysis has six phases: familiarisation with data, generating initial codes, searching for themes, reviewing themes, defining and naming themes, and producing the report. ${ }^{13}$ In our data analysis we followed a hybrid approach of qualitative methods of thematic analysis, drawing on both inductive (i.e. data-driven) and deductive (i.e. based on pre-conceived ideas) approaches. This was an iterative and reflexive process with the data collection and analysis being conducted concurrently. Indeed, we chose thematic analysis among other qualitative methods for its flexibility, while we position our study within the social constructionist epistemological tradition, according to which patterns of meaning and experience are socially produced and reproduced. ${ }^{13}$

As a first step, 18 broad thematic categories (nodes) were deductively generated and formed the code manual which can be found in online supplementary appendix 4. Each node contained two subcategories (subnodes): 'facilitators' and 'barriers' and then a third subcategory 'improvements' was added inductively during analysis due to participants commonly suggesting potential improvements to services. The second step involved the testing of 
the reliability of the coding template. A researcher (DS) with considerable experience of qualitative data analysis but not of health-related research coded all transcripts. NVivo software was used to aid this process. Then four transcripts were also coded independently by another author (JK), an academic GP who had some prior knowledge about the topic being researched through his clinical experience. Any differences between coding were discussed. No major conflicts arose. The third step involved the recoding of the entire dataset using NVivo software. Analysis of the interview transcripts at this stage was guided, but not limited, to the initial codes. Inductive codes were assigned to parts of data that described a new theme observed in the text. These new codes were either separate from or expanded a code from the original template. The final step focused on connecting the codes and identifying and clustering the main themes that emerged within the dataset. These broad thematic categories were further clustered into overarching themes and were assigned succinct descriptions that captured the essence of each theme. Coding clinics were also held among DS, JK, KIG and FSM to discuss coding and to shape overarching themes. In order to ensure that the final clustered themes were representative of the initially assigned codes, preceding stages were carefully scrutinised before proceeding to the interpretation of the coded text.

\section{Patient and public involvement}

The Research Advisory Group that guides this programme of research includes four stroke survivors or carers of stroke survivors. Their input has helped to guide the aims, objectives and methods of this study.

\section{RESULTS}

Participant details are provided in table 1 . We identified five overarching themes that capture the factors described by health professionals and health-service managers as influencing the minimisation of treatment burden and maximisation of patient capacity following a stroke. One key finding was that the factors identified were described as influential on the ability to provide person-centred care which in turn influenced treatment burden and patient capacity (see figure 1). The five themes uncovered were: healthcare system structure; resources; knowledge and awareness; availability of social care; and patient complexity. Tables 2 and 3 detail the barriers and facilitators, respectively, to providing care that minimises burden and maximises capacity within each overarching theme. In the following sections, we describe and discuss pertinent factors that were commonly reported by participants.

\section{Healthcare system structure}

Participants reported that the structure of the healthcare system they were operating in was hugely influential on their ability to provide low-burden, personalised care. This included the systems and processes in place to allow

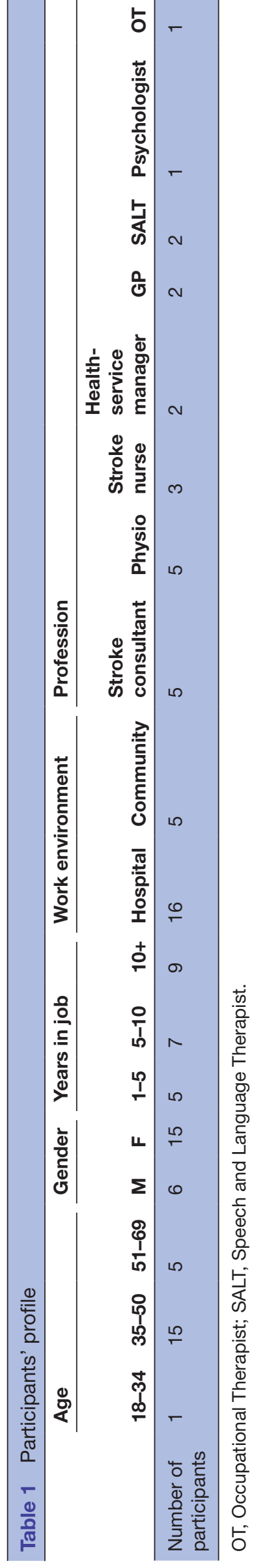




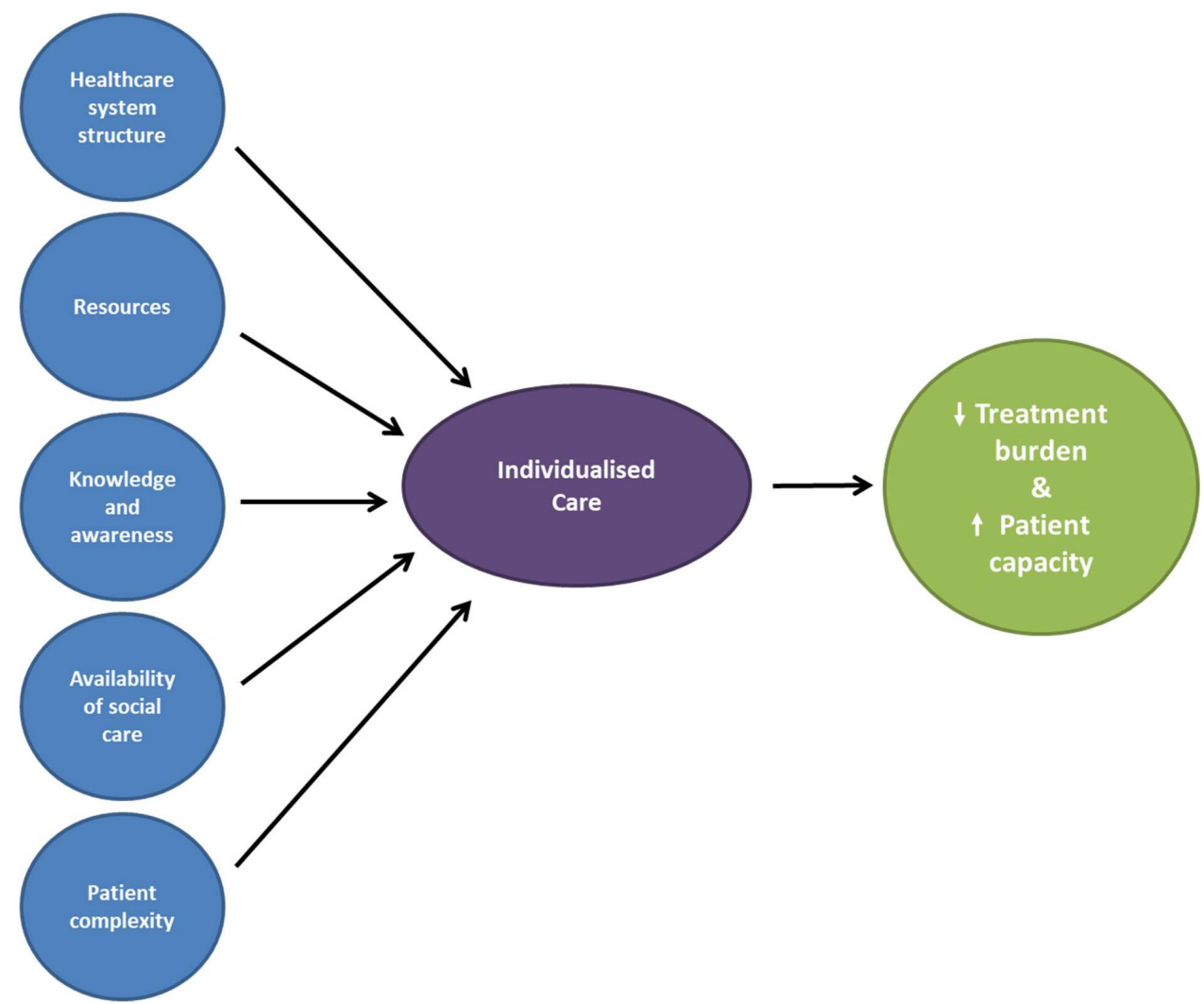

Figure 1 Areas in which treatment burden can be minimised and patient capacity can be maximised.

communication and coordination between health professionals, and to encourage autonomous working with flexibility in care provision.

A key obstacle identified by most of our participants was the lack of standardised communication procedures between and within work settings (i.e. hospital and community settings; primary and secondary care; health and social services). This issue was raised particularly by interviewees who work in the hospital setting, who seem to be in greater need of more structured communication procedures, for example, between health and social care:

As a consultant you are asking: has the referral been made, has it been received? Has someone been appointed, have we heard from them? [...] We are having to just constantly seek where we are up to on that process so there is no online information about where any of that is. It's all communicated by telephone. It's all proactive social workers who may update the ward, otherwise the ward is chasing that information. It's quite labour intensive to see where we are up to with things. (Participant 14)

Several interviewees, especially stroke consultants, reported that communication and coordination between health professionals can be particularly problematic in the discharge process:

It's sometimes quite difficult to track down social workers and to get the information that you need from social workers and perhaps to get access to them at a good time for patients as well. And I think a lot of discharges are delayed because of difficulties with that side of things. (Participant 9)

Most participants highlighted the importance of a system that fosters good communication between health professionals as well as collaborative working, for example, regular face-to-face multidisciplinary meetings and case conferences in the hospital setting:

In the inpatient setting I think the multi-disciplinary model helps because you have then got not just a physician view of the world, you've got the nurses and the therapists talking about the person's other limitations and if you have got a really good named nurse they will often know the sort of psychological concerns the person has as well. So you will get a really, a much more complete picture. So I think that works well although I was going to say it's time consuming but it's probably only you know these meetings are maybe only a bit over an hour a week all together for the stroke unit so I think that's a big plus. (Participant 11)

Participants also described working in an inflexible system where health professionals were discouraged from working autonomously due to rigid protocols and procedures. This opinion was expressed by more senior health professionals (i.e. $5+$ years in the job). This prevented the provision of individualised care as they felt unable to tailor care to their patient's needs. 
Table 2 Barriers to providing healthcare that minimises treatment burden and maximises patient capacity

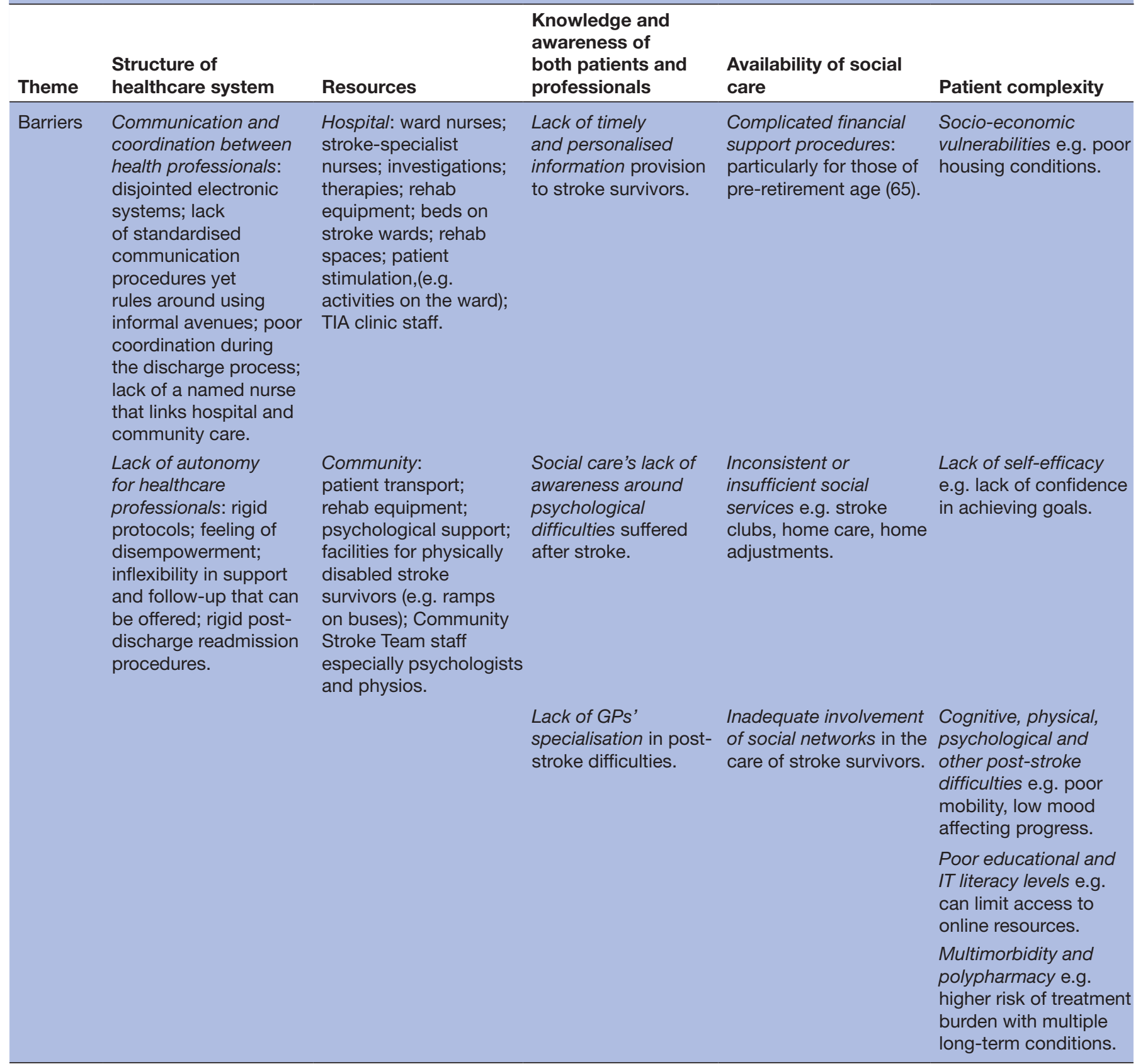

IT, Information Technology.

\section{Resources}

Resources in both the hospital and community were highlighted as important. A key resource issue in the secondary care setting was nursing staff shortages on the wards. This was raised by virtually all participants working in the hospital setting, irrespective of their profession:

The nursing staff are short staffed, they don't have two people that can walk round to the toilet so they use the machine called the steady to take them to the toilet which is a much easier, quicker way for them to do it but then that cuts back on that rehab potential so there is those kind of issues I would say but I think that harps back to probably the staffing issues overall. And having the time. I think the nurses don't have time to be rehab nurses. (Participant 3)

Limited access to in-hospital investigations was highlighted by almost all stroke consultants, which was reported as delaying progress of recovery and prolonging hospital stays. A shortage of psychologists in the community was also reported by almost all participants working in the community and this was described as having a detrimental impact on stroke survivors' self-efficacy and ability to adjust to new disabilities or other difficulties. Despite shortages in the community, many participants working 
Table 3 Facilitators to providing healthcare that minimises treatment burden and maximises patient capacity

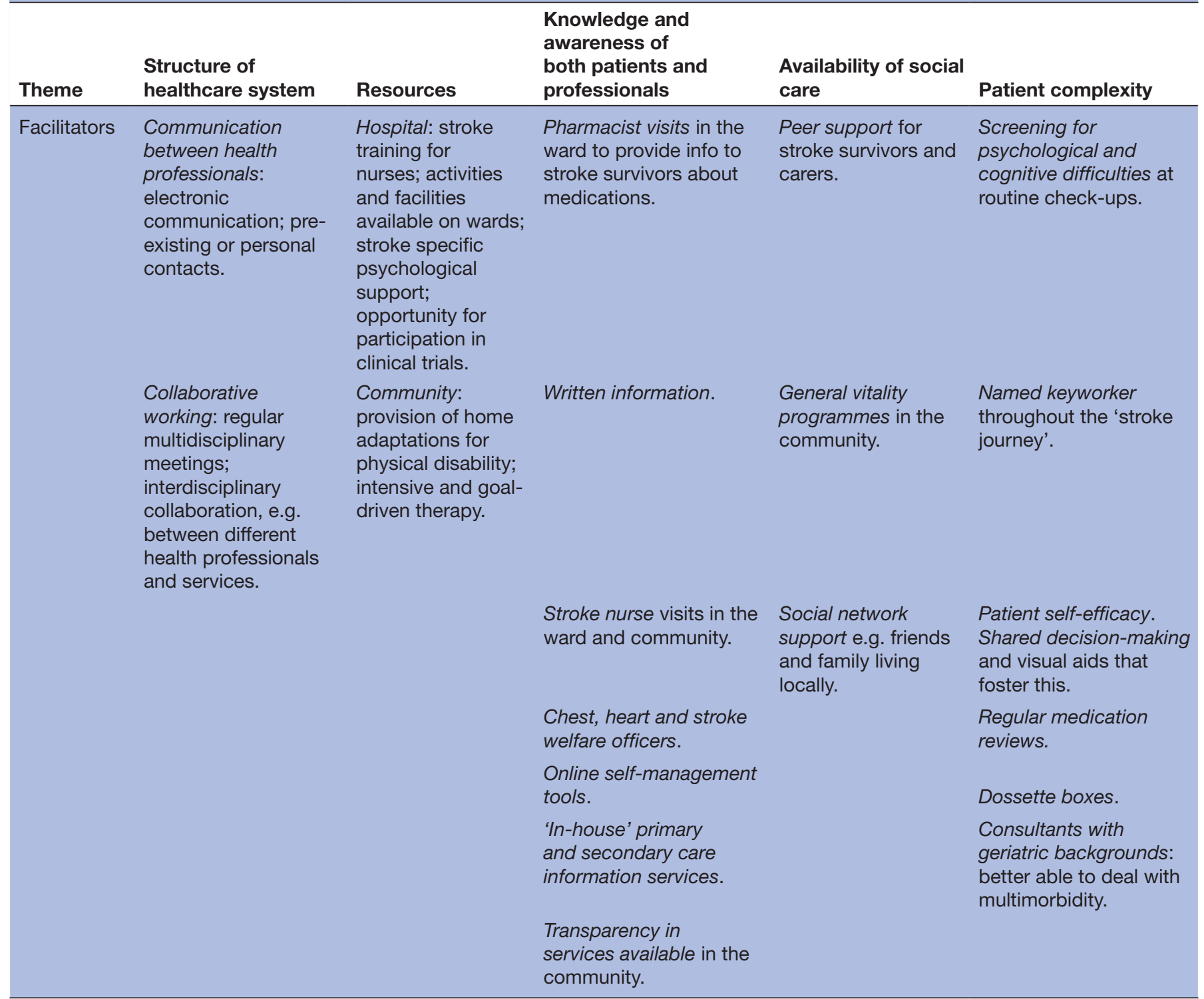

in the hospital setting praised the availability of in-house stroke-dedicated psychology services:

We have a strong and very healthy stroke psychology team in Glasgow and I think I'm really pleased with the extent to which that team works as part of the multi-disciplinary stroke service. I think it becomes a bit more fragmented when it goes in, when you come back into the community. I'm thinking about in an acute environment. From an acute perspective we have got a very good stroke/psychology team. (Participant 19)

\section{Knowledge and awareness of both patients and professionals}

Participants acknowledged that increasing stroke survivors' knowledge of the treatments and services available to them could lessen their treatment burden. They identified several factors that can hinder the successful transfer of information. One important obstacle identified by almost all stroke consultants and both health-service managers was the difficulty in providing person-centred information at the right time for the patient. For example, secondary care professionals described a lack of one-on-one time with patients and that any such time was limited to during the acute phase of stroke when retaining information may be difficult:

It would be great if there was more of a person assigned to you and you saw them right through the journey or you had a contact point who you could regulate input information if you needed to. I don't know if it would be easy to work but that would probably be an ideal from a patient's point of view. (Participant 1)

They reported that health professionals' knowledge was also important, for example, it was felt by some in the hospital setting that those working in social services and 
primary care may lack specialised knowledge about stroke recovery.

Stroke nurse, pharmacist and volunteer visits to stroke survivors on the ward and in the community were deemed to be important facilitators of increasing patients' knowledge and awareness of services:

We are fortunate here that we've got stroke nurse specialists who are sort of board employees and we've got two in ' $\mathrm{X}$ hospital' and one up at ' $\mathrm{Y}$ hospital' where our rehab unit is. All of the Greater Glasgow and Clyde hospitals have stroke nurse specialists and one of their specific roles is information provision to patients and their families. (Participant 15)

The existence of a written information booklet that had been made available by the health board called the "My Stroke booklet' was highlighted by many participants, particularly stroke consultants and nurses, as a helpful source of information to distribute to patients. However, a few of the interviewees indicated a shortage of these booklets in their work settings.

\section{Availability of social care}

Inconsistent or insufficient provision of social services in the community was mentioned by more than half of the participants working in the community setting:

Depending on the area that the person lives in, depends how quickly homecare get puts into place. So 'area A' is good, 'area B' is not. So we have to be very proactive about saying to 'area B' come on, come on these people need this and they need it now but it might not go into place quickly. (Participant 13)

The important role of informal social networks such as friends and family were highlighted as very important following discharge into the community:

Social networks can have a very positive or a negative impact on patients. You know, if people are isolated then they might find it harder to be able to manage their long-term condition. But I think certainly a lot of the successes we see are with patients who have got more supportive networks. (Participant 12)

In this regard, many participants from both settings argued for the enhancement of social network support, particularly for those with weak social networks, acknowledging their crucial role in the rehabilitation of stroke survivors.

\section{Patient complexity}

Many interviewees, particularly those working as physiotherapists, highlighted that it could be challenging to provide suitable, individualised care to those with complex post-stroke cognitive, physical or psychological difficulties:

There is always a challenge getting the right information to patients at the right time and I think with stroke patients that's particularly challenging because of the emotional issues immediately after a stroke and the cognitive issues and that the language issues obviously some people can't read information and taking on new information is very difficult. You are talking about patients with language problems, cognitive issues, their life turned upside down so they've got all sorts of psychological problems. (Participant 9)

Patient self-efficacy was commonly reported by those working in the hospital setting as influential on how care was provided, for example, shared decision-making was easier in a patient with confidence in achieving their goals. Multimorbidity and polypharmacy were other challenges cited by several participants working in the hospital setting, particularly stroke consultants, due to the increased workload of healthcare experienced by patients with multimorbidity and the increased risk of treatment interactions.

For complex patients, ensuring a sense of continuity throughout the rehabilitation process was deemed to be important to minimise treatment burden. Hence, the majority, particularly those working as physiotherapists, highlighted the importance of a named stroke nurse, or other designated person, throughout the patient journey:

If [stroke survivors] even had somebody they could phone or somebody came out to their house after they were home and said you know, these are the things that might happen or [...] if you have got any concerns or problems give us a phone. I think there should be regular contact, not necessarily with the stroke nurses in the hospital but again through health centres or GP surgeries or whatever they should be, a stroke nurse or somebody similar who can get into the community and just, not necessarily know everything about it but be able to say this is the number you can call. (Participant 4 )

More experienced health professionals (i.e. 10+ years in job) noted that in recent years the role of the stroke nurse has been limited to the hospital setting, with rare visits in the community environment. This was felt to be an important resource issue that has negatively impacted on the provision of care for complex patients.

\section{DISCUSSION}

\section{Summary of findings}

This is the first study to explore health professional and healthcare managers' perspectives on barriers and facilitators to providing healthcare that is minimally burdensome for stroke survivors while enabling their recovery. Five major factors were reported as being influential on providing low burden healthcare: healthcare system structure; resources; knowledge and awareness; availability of social care and patient complexity. These factors were reported as influencing treatment burden and patient capacity through impacting health professionals' abilities to provide person-centred care. Person-centred care is healthcare that is tailored towards an individual's circumstances and preferences, with flexibility in how care is delivered and 
shared decision-making between patient and health professional. Person-centred care prioritises the needs and wants of the patient taking careful consideration of their physical, psychological and social circumstances at the point in time when care is being delivered. Many participants described working in an inflexible system where communication and coordination between specialities is substandard and key resources such as ward nursing staff and community psychologists are lacking. Educating patients about their treatments was felt to be very important, yet the interviewees often reported difficulties in obtaining the time and materials to adequately do this. Patient complexity was acknowledged as becoming increasingly common and having a major impact on the way healthcare is provided, for example, it may be harder to minimise treatment burden and maximise patient capacity in a frail patient with multiple long-term conditions. Deficiencies in the availability of social care were reported as an important factor affecting patient capacity, particularly if the patient lacked an informal social network who could help them manage their health. All participants acknowledged the importance of providing healthcare that minimises treatment burden and maximises patient capacity, yet they often felt they were prevented from being able to do so by the health and social care system that they worked in. Findings suggest that changes at the macro level are needed to foster an environment that supports the provision of person-centred, low-burden care for stroke survivors. Commonly suggested improvements made by participants to overcome the barriers reported are presented in table 4 . One example was the implementation of a named discharge coordinator who could facilitate a smooth transition into the community, improve communication between health and social services and act as a contact for patients. Another example was initiation of routine follow-up reviews for more complex, multimorbid patients after discharge into the community, in order to deal with issues such as medicine reconciliation.

\section{Strengths and limitations}

Qualitative research does not aim to be representative; therefore, the small sample size and purposive sampling technique should not be viewed as a limitation. However, findings should be considered as explorative and not definitive, and as all participants were employed in one geographical area, it would be beneficial to additionally study a group of health professionals from another locality. One key strength was that data saturation was reached, another was the inclusion of health professionals across the stroke survivor journey, from acute through to primary care. Double coding of a subset of interviews enhanced coding reliability.

\section{How does this compare to previous research?}

Treatment burden is a relatively new concept in the medical literature that has been infrequently examined in stroke. While this is the first study to examine professional perspectives on barriers and facilitators to reducing treatment burden and maximising capacity in those with stroke, there has been some published literature on this in relation to patient perspectives. We previously conducted a large systematic review of the qualitative literature ${ }^{10}$ and conducted our own qualitative study ${ }^{8}$ to examine the

Table 4 Suggested improvements per theme

\begin{tabular}{|c|c|c|c|c|c|}
\hline Theme & $\begin{array}{l}\text { Structure of } \\
\text { healthcare system }\end{array}$ & Resources & $\begin{array}{l}\text { Knowledge and } \\
\text { awareness of } \\
\text { both patients and } \\
\text { professionals }\end{array}$ & $\begin{array}{l}\text { Availability of } \\
\text { social care }\end{array}$ & Patient complexity \\
\hline \multirow[t]{3}{*}{$\begin{array}{l}\text { Suggested } \\
\text { improvements }\end{array}$} & $\begin{array}{l}\text { Introduction of } \\
\text { a named person } \\
\text { to facilitate } \\
\text { communication } \\
\text { between services, } \\
\text { e.g. 'discharge } \\
\text { coordinator'. }\end{array}$ & $\begin{array}{l}\text { Investment in } \\
\text { the provision of } \\
\text { psychological } \\
\text { support services in } \\
\text { the community. }\end{array}$ & $\begin{array}{l}\text { Tailored information } \\
\text { provision to } \\
\text { stroke survivors in } \\
\text { accessible language } \\
\text { and format. }\end{array}$ & $\begin{array}{l}\text { Enhancement of } \\
\text { social network } \\
\text { support, } \\
\text { particularly for } \\
\text { those with weak } \\
\text { social networks, } \\
\text { e.g. prompt } \\
\text { support group } \\
\text { referral. }\end{array}$ & $\begin{array}{l}\text { Routine patient } \\
\text { follow-up reviews and } \\
\text { medication reconciliation } \\
\text { in the community. }\end{array}$ \\
\hline & $\begin{array}{l}\text { Autonomous working } \\
\text { to enable person- } \\
\text { centred care. }\end{array}$ & $\begin{array}{l}\text { Increased numbers } \\
\text { of nursing staff } \\
\text { in hospitals, } \\
\text { particularly in } \\
\text { stroke wards. }\end{array}$ & $\begin{array}{l}\text { Designated contact } \\
\text { person throughout } \\
\text { the 'stroke journey'. }\end{array}$ & & \\
\hline & $\begin{array}{l}\text { Improved } \\
\text { communication } \\
\text { between services } \\
\text { and specialities, e.g. } \\
\text { ability to call a named } \\
\text { person or meet face- } \\
\text { to-face. }\end{array}$ & & & & \\
\hline
\end{tabular}


patient experience of treatment burden in stroke and the factors that influence patient capacity. The aspects of care that stroke survivors described as being influential on treatment burden and patient capacity were very similar to those reported here by health professionals: substandard information provision; poorly coordinated care, particularly during discharge from hospital into the community; a lack of continuity of care; long waiting times for investigations and poor access to psychological services in the community. Both health professionals and stroke survivors emphasised the importance of person-centred care. Another recent systematic review examined stroke survivors' and their caregivers' experiences of community healthcare. ${ }^{15}$ Although focused on care in the community and not aimed at examining treatment burden, findings again resonated with professional perspectives reported here in that stroke survivors reported continuity of care, access to psychological services, information provision, access to social care, communication between services and fluidity of care as influential on their experience of healthcare. A recent metareview examined systematic reviews of qualitative studies that had examined the experience of self-management for stroke survivors. ${ }^{11}$ Again, patients identified similar issues to those we have found with health professionals in this study, particularly relating to the varying needs across the patient journey and a requirement for better information provision, social care, patient-professional communication and psychological support in the community. The similarities in findings between these previous studies of stroke survivors and our current study of health professionals strengthen the argument for system-level change in the way we provide healthcare that allows health professionals to deliver person-centred care.

\section{What further research is needed?}

Findings from this study of health professionals and our previous examination of the patient experience of treatment burden highlight the need to develop interventions aimed at minimising treatment burden and maximising capacity in those with stroke. The current study should inform the development of such complex interventions. Examples of potential interventions include: introduction of electronic systems to enable better communication between specialities; a named person throughout the patient journey (both in the hospital and the community); a routine review in primary care soon after discharge from hospital; and online access to a stroke community for peer support. To ascertain if such interventions are successful, it is important to be able to measure treatment burden in those with stroke, and therefore development of a patient-reported measure (PRM) of treatment burden for this patient population is required. PRMs of treatment burden have recently been developed for use in other patient groups ${ }^{16-18}$ and augmentation of these with validation in a stroke population may be suitable.

\section{CONCLUSION}

This study gives insight into the perspectives of healthcare managers and professionals regarding the barriers and facilitators to providing healthcare that minimises treatment burden and maximise patient capacity to manage health. Findings resonate greatly with our previous studies of the perspectives of stroke survivors. ${ }^{8}{ }^{10}$ A key finding was that the provision of person-centred care is fundamental. The findings should be used to inform the development of future complex interventions aimed at minimising treatment burden for stroke survivors and maximising their capacity to manage health problems.

Twitter Frances S Mair @FrancesMair and Katie I Gallacher @GallacherKatie

Acknowledgements Research Advisory Group members: Roger Lambert, Tim Morrow, David Jones, Moira Campbell.

Contributors KIG and FSM contributed to the design of the project. JK conducted the interviews. DS conducted data analysis and JK double coded a subset of the transcripts. KIG, FSM, DS and JK all took part in coding clinics. DS and JK wrote a first draft of the paper and all authors reviewed drafts and approved the final version.

Funding This study was funded by the Stroke Association (TSA 2017/01) and Greater Glasgow Endowment Fund (GN17ST385).

Competing interests KIG received funding from The Stroke Association to complete this work. FSM received payment for educational activities from Janssen outside the submitted work.

Patient and public involvement Patients and/or the public were involved in the design or conduct or reporting or dissemination plans of this research. Refer to the Methods section for further details.

Patient consent for publication Not required.

Ethics approval Ethical approval was granted by the University of Glasgow, College of Medical, Veterinary \& Life Sciences (MVLS) Ethics Committee (project no. 200170014).

Provenance and peer review Not commissioned; externally peer reviewed.

Data availability statement Data are available upon request to the corresponding author. As data contain information which may lead to the identification of study participants, funding would be required to support anonymisation of the data.

Open access This is an open access article distributed in accordance with the Creative Commons Attribution Non Commercial (CC BY-NC 4.0) license, which permits others to distribute, remix, adapt, build upon this work non-commercially, and license their derivative works on different terms, provided the original work is properly cited, appropriate credit is given, any changes made indicated, and the use is non-commercial. See: http://creativecommons.org/licenses/by-nc/4.0/.

ORCID iD

Katie I Gallacher http://orcid.org/0000-0001-8620-8758

\section{REFERENCES}

1 Gallacher K, May CR, Montori VM, et al. Understanding patients' experiences of treatment burden in chronic heart failure using normalization process theory. Ann Fam Med 2011;9:235-43.

2 May CR, Eton DT, Boehmer K, et al. Rethinking the patient: using burden of treatment theory to understand the changing dynamics of illness. BMC Health Serv Res 2014;14:281.

3 Eton DT, Ramalho de Oliveira D, Egginton JS, et al. Building a measurement framework of burden of treatment in complex patients with chronic conditions: a qualitative study. Patient Relat Outcome Meas 2012;3:39-49.

4 NICE. Multimorbidity: clinical assessment and management, 2016. Available: https://www.nice.org.uk/guidance/ng56 [Accessed Aug 2019].

5 May C, Montori VM, Mair FS. We need minimally disruptive medicine. BMJ 2009;339:b2803.

6 Mair FS, May CR. Thinking about the burden of treatment. BMJ 2014;349:g6680. 
7 Shippee ND, Shah ND, May CR, et al. Cumulative complexity: a functional, patient-centered model of patient complexity can improve research and practice. J Clin Epidemiol 2012;65:1041-51.

8 Gallacher KI, May CR, Langhorne P, et al. A conceptual model of treatment burden and patient capacity in stroke. BMC Fam Pract 2018;19:9.

9 Stroke Association. State of the nation: stroke statistics, 2018. Available: https://www.stroke.org.uk/resources/state-nation-strokestatistics [Accessed Aug 2019].

10 Gallacher K, Morrison D, Jani B, et al. Uncovering treatment burden as a key concept for stroke care: a systematic review of qualitative research. PLoS Med 2013;10:e1001473.

11 Pearce G, Pinnock H, Epiphaniou E, et al. Experiences of selfmanagement support following a stroke: a Meta-Review of qualitative systematic reviews. PLoS One 2015;10:e0141803.

12 Gallacher KI, Batty GD, McLean G, et al. Stroke, multimorbidity and polypharmacy in a nationally representative sample of $1,424,378$ patients in Scotland: implications for treatment burden. BMC Med 2014;12:151.
13 Braun V, Clarke V. Using thematic analysis in psychology. Qualitative research in psychology. 2 edn. London: Routledge, 2006: 77-101.

14 Daly J, Kellehear A, Gliksman M. The public health researcher: a methodological approach. Oxford University Press, 1997.

15 Pindus DM, Mullis R, Lim L, et al. Stroke survivors' and informal caregivers' experiences of primary care and community healthcare services - A systematic review and meta-ethnography. PLoS One 2018;13:e0192533.

16 Eton DT, Yost KJ, Lai J-S, et al. Development and validation of the patient experience with treatment and self-management (PETS): a patient-reported measure of treatment burden. Qual Life Res 2017;26:489-503.

17 Tran V-T, Harrington M, Montori VM, et al. Adaptation and validation of the treatment burden questionnaire (TBQ) in English using an Internet platform. BMC Med 2014;12:109.

18 Duncan P, Murphy M, Man M-S, et al. Development and validation of the multimorbidity treatment burden questionnaire (MTBQ). BMJ Open 2018;8:e019413. 